\title{
Prosthodontic Management of External Inflammatory and Replacement Resorption of Avulsed Replanted Permanent Incisors
}

Anil Kumar ${ }^{1}$

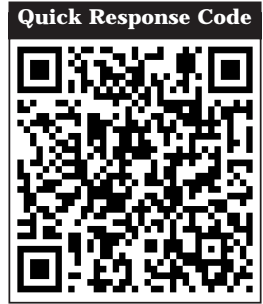

doi : $10.5866 / 2014.631641$

1Senior lecturer

Department of prosthodontics

Army college of dental sciences

Secunderabad

India

\section{Article Info:}

Received: April 10, 2014

Review Completed: May 11, 2014

Accepted: J une 8, 2014

Available Online: October, 2014 (www.nacd.in)

(c) NAD, 2014 - All rights reserved

Email for correspondence:

anilks.undefined@gmail.com

\begin{abstract}
:
External inflammatory and replacement resorption are mainly caused when avulsed teeth are replanted following traumatic dental injury. Resorption may ultimately lead to loss of tooth. This situation is mainly common in young and adolescents but may affect elderly also. Loss of tooth might lead to psychological depression of a young patient. Prosthodontic rehabilitation should focus on immediate care of the patient. In the present day tremendous advances have occurred in the field of implant dentistry. I mmediate implant placement cannot be ruled out in rehabilitation of replacement resorption cases, but there are certain limitations and case to case variations do occur when planning for implant placement. At times a fixed dental prosthesis becomes the possible substitute when there are limitations for implant placement. A case is presented illustrating resorption of replanted maxillary incisors treated with a fixed dental prosthesis having ovate pontics.
\end{abstract}

Key words: External resorption, ovate pontic.

\section{Introduction}

Traumatic injuries of incisors occur very frequently in young and adolescents. Root resorption, root canal obliteration, interruption in root formation and periapical lesions are the most common sequelae of traumatic injuries to the teeth. ${ }^{1}$ Root resorption is a dental complication followed by replantation of an avulsed tooth that can lead to tooth extraction. The aetiology of root resorption requires two phases: injury and stimulation. ${ }^{2,3}$ I njury is related to non mineralized tissues covering the external surface of the root, the pre-cementum or internal surface of the root canal, the pre-dentin. The injury is similar to several types of root resorption and may be mechanical following dental trauma, surgical procedures and excessive pressure of an impacted tooth or tumour. Denuded mineralized tissue is colonized by multinucleated 
cells which initiate the resorption process. ${ }^{4}$ When pulp necrosis occurs following luxation of teeth; the necrotic tissue is susceptible to bacterial contamination. The combination of bacteria in the root canal and cemental damage on the external root surface results in external inflammatory root resorption ultimately leading to tooth loss. ${ }^{5}$ Following traumatic loss of anterior tooth, it is important that an immediate replacement is provided in order to avoid aesthetic masticatory and phonetic difficulties and to maintain the edentulous space. ${ }^{6}$ Cosmetic demands, functional needs, treatment sequencing are primary concerns that need to be addressed. I mmediate implant placed in the extraction sites followed by temporization should be the first treatment of choice if the quantity and quality of the bone meet the criteria for an immediate implant placement. If the criteria for implant placement are not met then treatment plan has to be changed. The next immediate alternative that can be thought of is fabrication of a removable acrylic immediate denture placed after tooth extraction, but they are bulky and since they have to be removed and cleaned by the patient it might cause discomfort to the patient especially if the patient is an adolescent. So the last alternative remaining is a fixed dental prosthesis where in the abutment teeth are adequately prepared before the extraction of the resorbed tooth and an immediate interim fixed dental prosthesis with ovate pontics can be inserted. This has added advantage where in the patient is immediately rehabilitated and also the use of ovate pontics creates a naturally appearing emergence profile for the final restorations. This article describes a case of replanted maxillary incisor teeth following avulsion due to a road traffic accident. Replacement resorption of the teeth occurred after 2 years because of which the teeth had to be salvaged. The patient was immediately rehabilitated after extraction with an ovate pontic supported fixed partial interim denture.

\section{CASE REPORT}

A patient aged twenty years reported to Department of Prosthodontics Military Dental Centre (MDC), Secunderabad with a chi ef complaint of pain and discoloration of maxillary left central and lateral incisor. His medical history was noncontributory. He had experienced a bike accident that resulted in the avulsion of his maxillary left central and lateral incisor and incisal edge fracture of maxillary right central and lateral incisors. The patient's parents reported to a nearby dentist with the avulsed teeth and it was replanted within one hour of its avulsion and splinting of teeth was done. Root canal treatment of the replanted teeth and the fractured right incisor teeth was done after one week. Following replantation and root canal treatment of teeth the patient was symptom free for two years. The teeth also got discoloured over a period of time. The patient reported to MDC only when he started experiencing pain and heaviness in the maxillary anterior region. Clinical findings with maxillary left central and lateral incisors confirmed patient's complaint. The teeth were tender on percussion with associated discoloration (Figure 1). An intraoral Radiovisiography (RVG) revealed root resorption in relation to both the left central and lateral incisors. It was decided to extract the teeth and rehabilitate with an artificial prosthesis. The patient was a fashion designer and was very much concerned about his aesthetics immediately after extraction. He was totally demoralised after the course of treatment was explained to him so an immediate rehabilitation following extraction was planned. I mmediate implant supported prosthesis was the first choice. A head and neck CT scan (SENSATION-40, Siemens) of the patient was done to assess the bone density around the resorbed teeth but the bone density was around 875 Hounsefield units inferring a D4 bone quality (Misch Classification), so the possibility of immediate implant supported prosthesis was ruled out. The patient was given a second choice of rehabilitation with an immediate removable partial denture for 6 months followed by placement of implants once the bone quality improved. The patient was very reluctant in wearing a removable partial denture. The last treatment option remaining was rehabilitation with ovate pontics supported fixed dental prosthesis for the extracted teeth. Since RCT was done in maxillary right central and lateral incisors they had to be restored with porcelain crowns. Diagnostic models were prepared. A mock tooth preparation and 


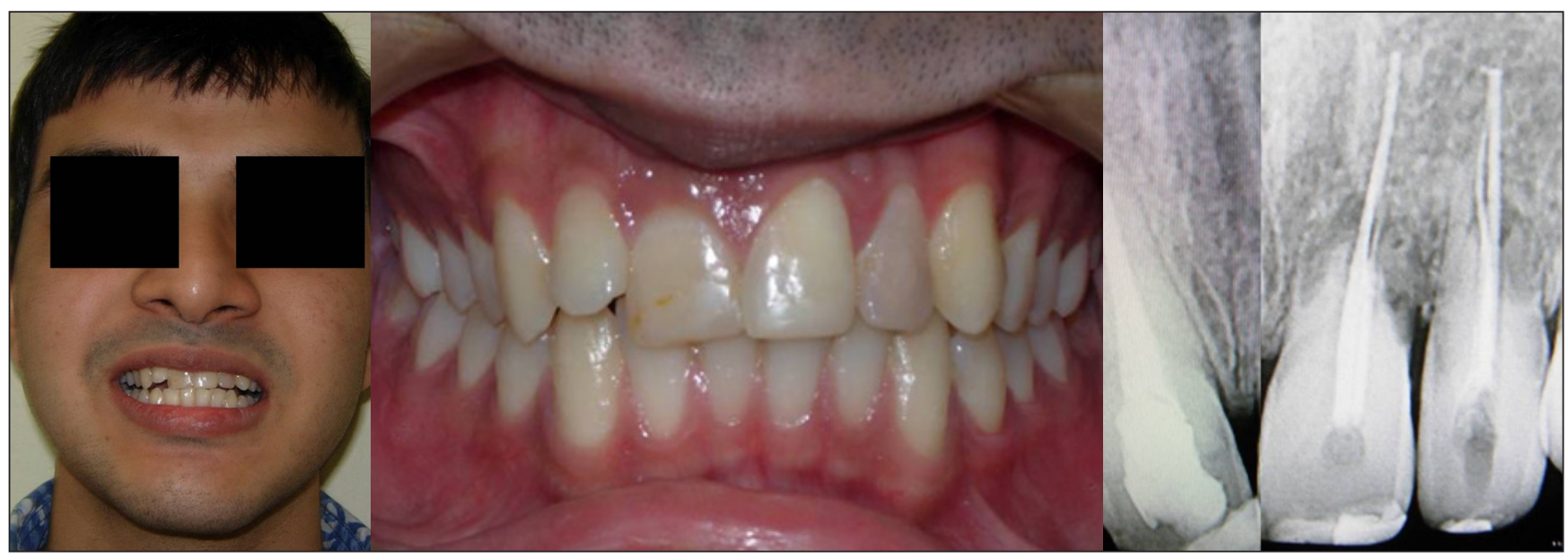

Figure 1: Pre-operative picture showing discoloration and root resorption in relation to both the left central and lateral incisors

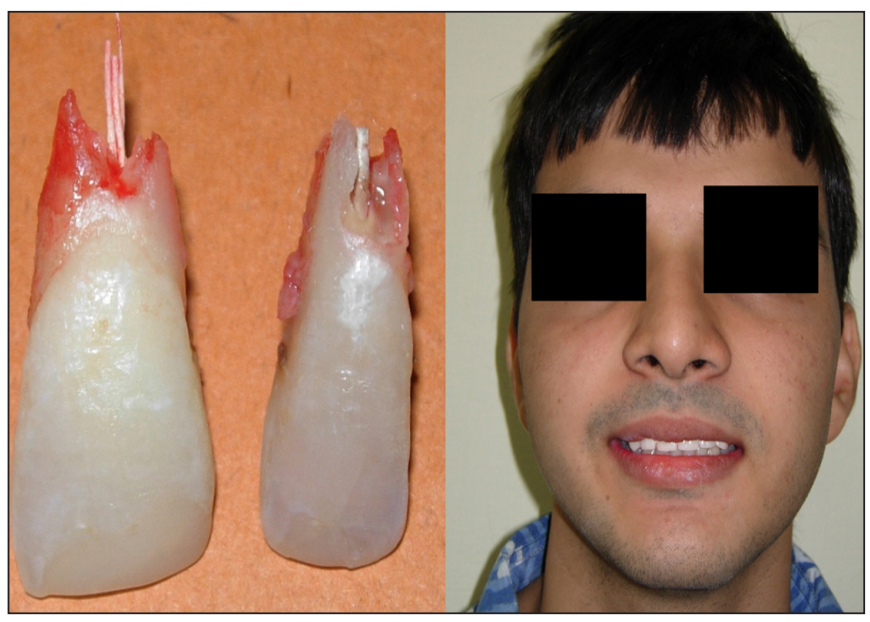

Figure 2: Provisionalisation.

diagnostic wax-up was done to visualize the final aesthetic outcome and also to educate the patient. The waxed models were flasked and heat cure interim fixed partial denture was fabricated. The tooth preparation of maxillary right canine, lateral, central incisors and maxillary left canine having shoulder with bevel margins was done. (An ovate pontic design was planned for the extracted left central and lateral incisors). Gingival retraction (Ultrapak, Ultradent) of all the prepared teeth was performed. Maxillary left central and lateral incisors were extracted and the interim fixed partial denture was relined chair side with autopolymerising resin (DPI , Cold Cure tooth colored resin) (Figure 2). The fixed partial denture was cemented using eugenol

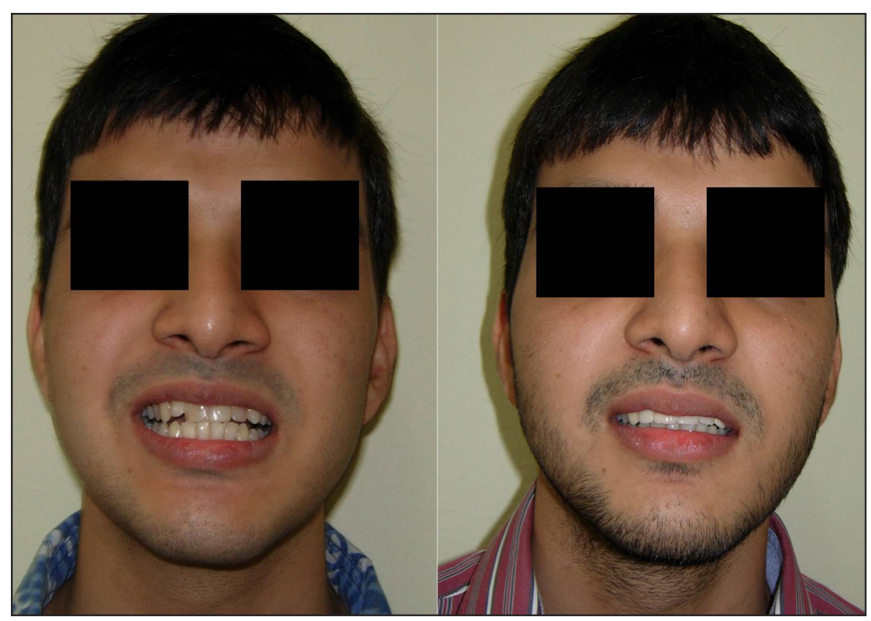

Figure 3: Post Operative picture showing insertion of porcelain fused to metal fixed partial denture.

free cement (RelyX ${ }^{\mathrm{TM}}$, Temp NE, 3M ESPE). The patient was evaluated periodically till 6 months. At the end of 6 months porcelain fused to metal fixed partial denture was fabricated and inserted (F igure 3). The patient was evaluated after one year. The patient was emotionally stable and had participated in various fashion shows.

\section{DISCUSSION}

Traumatic injuries of teeth frequently occur in children and adol escents. Avulsions of anterior teeth compromise aesthetic, mechanical and biological functions in an individual. Replantation is the first choice of treatment for avulsions under clinical conditions. Chappuis et al reported that the survival 
rate of a tooth that was completely avulsed and replanted was $95.6 \%$ one year after replantation. ${ }^{7}$ They suggested that the induction of replacement of resorption after replantation was influenced by the time lag between avulsion and replantation during which the tooth is exposed to dry conditions. Donaldson et al reported that the time limit for successful replantation was 15 minutes while Mclntyre et al reported a time limit of 20 minutes if the tooth had been exposed to dry conditions. ${ }^{8,9}$ In the present case complete root resorption of teeth had occurred 2 years after replantation. This could be explained by the poor condition of the periodontal ligament probably due to the exposure of theavulsed tooth to dry conditions for more than an hour. The replacement resorption might have also been due to improper techniques such as the avulsed tooth not being returned to its appropriate position in the alveolar socket. It is very much essential to adequately educate school children and pool facility personnel regarding the immediate management of traumatic injuries to stock preservative solution for avulsed teeth at places where trauma to teeth often occur to establish a tie-up between such places and specialized dental clinics and to improve the knowledge of both dentists and patients regarding management of traumatic injuries. ${ }^{10}$

When implants are not an option for treatment of a case alternative treatment plans need to be thought of. Fabrication of a fixed dental prosthesis taking the support of teeth adjacent to the edentulous space has been followed from ages. A properly fabricated fixed dental prosthesis can be more aesthetically pleasing for the patient which sometimes cannot beachieved by implant prosthesis. Pontics of fixed partial denture have to fulfil aesthetic, functional and hygienic requirements. The ovate pontic was developed to fulfil all the above criteria. A removable partial denture also cannot be ruled out in treating patients who have suffered tooth loss due to a traumatic injury.

\section{CONCLUSION}

To conclude certain guidelines have to be followed when treating avulsed permanent teeth. Extraoral time $\mathbf{2 0}$ minutes or less is ideal and the tooth should be soaked in preservative solution of cold milk. A tooth with open apex may revascularize. Splinting of replanted teeth has to be followed. Lastly sequencing of treatment based on the clinical findings has to be followed.

\section{REFERENCES}

1. Cardoso M, Rocha MJ C. I dentification of factors associated with pathological root resorption in traumatized primary teeth. Dental Traumatol 2008; 24(3):343-349.

2. Tronstad L. Root resorption- etiology, terminology and clinical manifestations. Endod Dent Traumatol 1988; 4:241252.

3. Andreasen J O, Hjorting-Hansen E. Replantation of teeth Part I. Radiographic and clinical study of 110 human teeth replanted after accidental loss. Acta Odontol Scand 1966; 24:263-286.

4. Friedman S, Rotstein I, Libfeld H, Stabbola A, Heling I. Incidence of external root resorption and esthetic results in 58 bleached pulpless teeth. Endod Dent Traumatol 1988; 4:23-26.

5. Trope M. Clinical management of the avulsed tooth: present strategies and future directions. Dental Traumatol 2002; 18:1-11.

6. Ulusoy AT, Cehreli ZC. Provisional use of a natural tooth crown following failure of replantation: A case report. Dent Traumatol 2008; 24:96-99.

7. Chappuis V, von Arx T. Replantation of 45 avulsed permanent teeth: a 1 year follow up study. Dent Traumatol 2005; 21:289-296.

8. Donaldson M, Kinirons MJ . Factors affecting the time of onset of resorption in avulsed and replanted incisor teeth in children. Dent Traumatol 2001; 17:205-209.

9. Mclntyre J D, Lee J Y, Trope M, Vann WF J r. Management of avulsed permanent incisors a comprehensive update. Pediatr Dent 2007; 29:56-63.

10. Kostopoulou MN, Duggal MS. A study into dentists' knowledge of the treatment of traumatic injuries to young permanent incisors. Int J Paediatr Dent 2005; 15:10-19.

\section{Gain quick access to our journal online View our journal at www.nacd.in}

